\title{
ДОГОВОРНЫЕ ОТНОШЕНИЯ В СИСТЕМЕ ВЫСШЕГО ОБРАЗОВАНИЯ КАК ОСНОВА ОБЕСПЕЧЕНИЯ КАЧЕСТВЕННОЙ ПОДГОТОВКИ БУДУЩИХ СПЕЦИАЛИСТОВ
}

\section{CONTRACTUAL RELATIONS \\ IN THE HIGHER EDUCATION SYSTEM \\ AS A BASIS FOR ENSURING HIGH- QUALITY TRAINING OF FUTURE SPECIALISTS}

\section{A. Vlasov \\ T. Shtepa \\ D. Morkovkin}

Summary: A modern specialist should not only be erudite, but also have the necessary set of competencies that will allow him to solve the most complex tasks that are set before him. to get a high-quality education, you can use a huge number of courses that help you master a particular profession, but to get a high-quality education that allows you to become a competent specialist, the best solution is to conclude a contract with a higher educational institution and complete a full course of study - bachelor's, master's, specialty. It is classical higher education that is designed to be the very "foundation" that allows you to become a competent specialist capable of solving complex and extraordinary tasks.

Keywords: education, contract, higher education, student, educational services.

\author{
Власов Александр Викторович \\ К.э.н., дочент, ФГАОУ ВО "Российский университет \\ транспорта" (МИИТ), Москва \\ alessandro.vlasov@mail.ru \\ Шmеna Татьяна Владимировна \\ аспирант, ФГАОУ ВО "Российский университет \\ транспорта" (МИИТ), Москва \\ t.v.shtepa@mail.ru \\ Морковкин Дмитрий Евгеньевич \\ К.э.н., доцент, ФГАОУ ВО "РоссийскИй университет \\ транспорта" (МИИТ), Москва \\ MorkovkinDE@mail.ru
}

Аннотация: Современный специалист должен быть не только эрудирован, но и обладать необходимым набором компетенций, которые позволят решать ему самые сложные задачи, стоящие перед ним. Для получения качественного образования можно воспользоваться огромным количеством курсов, которые помогают освоить ту или иную профессию, но для получения качественного образования позволяющее стать грамотным специалистом, самое лучше решение - это заключить договор с высшим учебным заведением и пройти полный курс обучения - бакалавриат, магистратура, специалитета. Именно классическое высшее образованием призвано быть тем самым «фундаментом» позволяющим стать грамотным специалистом способным решать сложные и неординарные задачи.

Ключевые слова: образование, договор, высшее образование, студент, образовательные услуги.

го регулирования высшего образования так нуждается в детальном и четком урегулировании сторон. Также остро встает необходимость в новейших практических и теоретических разработках в изучении договорных отношений в области высшей общеобразовательной деятельности.

История развития договорных отношений в области образования на примере Римской империи и РФ начала и середины 20 века.

В римском праве договор также назывался контрактом, соглашением, или, по-другому, «contractus». Для Рима гражданско-правовой договор означал появление определенной договоренности вполне конкретного содержания.

Имеет место еще одно определение договора или соглашения для Римской империи - это обязательственное правовое отношение. В этом случае правовой договор был субъективным юридическим случаем. 
Данный юридический случай был основан на личной связи между определенными субъектами правовых отношений. Личная связь имелась в определенной альтернативе для того, который являлся заинтересованной стороной. Гражданское лицо, которое являлось заинтересованной стороной, могло требовать от другого субъекта, являющегося должником, определенного, нужного поведения.

Также под правовым договором представляется сама юридическая форма. В этой форме указанное обязательственное правовое и гражданское отношение в неизбежном порядке присутствует.

В науке гражданского права в начале и середине 20 века в Российской Федерации (на то время в Советском Союзе) обязательные правовые отношения в определенной степени были исследованы учеными, которые именовались цивилистами. Данные ученые работали до революции 1917 г. Самыми известными учеными-цивилистами того времени, которые занимались обязательными правовыми отношениями в науке гражданского права являлись - Егоров Н.Д. и Пугинский Б.И.

Очень точно определена концепция многозначности в определении «договор» в трудах юридической тематики Иоффе О.С. Данный ученый исследователь признавал договор, как соглашение нескольких граждан о возникновении, прекращении или изменении определенных гражданских правовых отношений.

Еще Иоффе О.С. писал: «Договор - это обязательство, которое получается из данного соглашения. В определенных моментах договор означает официальный документ, который фиксирует случай появления обязательства по воле его субъектов». Правовой договор оказания услуг в области высшего образования включает в себя определенные особые условия, как юридический факт, так и обязательное правовое отношение.

Ученые-исследователи (цивилисты), которые были названы ранее, при проведении исследований договорных отношений в области высшего образования, признавали гражданскую и правовую природу определенного договора. На сегодняшнее время в Федеральном законе «Об образовании в Российской Федерации» имеется статья п. 54 - «Договор на образование».

При всем этом, юридические отношения, которые формируются между людьми, получающими образовательные услуги и образовательным учреждением - отношения, которые были заключены при помощи договора. Стороны в данном конкретном случае выступают как равноправные партнеры.
Правовой договор, в котором прописаны возмездные образовательные услуги, обычно оформляется в письменной форме между гражданским субъектом, который желает получить образовательные услуги или физическим (юридическим) лицом, обязующимся оплатить обучение, и образовательным учреждением.

В договоре, который предназначен для предоставления различных возмездных образовательных услуг, должны быть прописаны следующие главные моменты и учебные параметры образования:

— вид предоставляемой образовательной услуги;

- уровень учебной программы;

- направленность образования;

- срок освоения учебной программы, то есть продолжительность обучения;

- форма образования;

- полная стоимость учебных услуг и форма оплаты.

Необходимо отметить, что повышение стоимости образовательных услуг руководством образовательного учреждения после заключения гражданского договора не допустимо. Исключение составляет только тот случай, когда произошла девальвация российского рубля, но предусмотренного основными характеристиками федерального бюджета России на определенный финансовый год и плановый период. В указанном случае изменение стоимости изменяется на процент инфляции.

Стоимость образовательных услуг, размещенная на официальном сайте любого высшего учебного заведения, должна быть такая же, как и в договоре на день его заключения. Гражданско-правовой договор о предоставлении образовательных услуг не может включать в себя пункты, которые бы ограничивали права граждан, имеющих право на получение высшего образования определенной направленности и уровня, подавших заявление о приеме на обучение в данное образовательное учреждение, и обучающихся.

Также в образовательном договоре не может быть сведений, которые бы снижали уровень обучения поступающим в высшие учебные заведения (далее - ВУзы) людей и уже обучающимся гражданам по сравнению с условиями, установленными законодательством РФ об образовании. Если же такие условия в образовательном договоре все же по каким-либо причинам имеются - они не подлежат применению, так как они находятся вне рамок закона.

Правовой договор на образовательные услуги в сфере высшего образования в Российской Федерации может быть расторгнут в следующих случаях:

- исполнение обязательств по договору, которые были даны администрацией высшего учебного 
заведения может быть прекращено в одностороннем порядке в случае бездействия обучающегося. То есть, если гражданин, который по правовому договору оплатил услуги, вдруг перестал без уважительных причин посещать занятия;

- если гражданский субъект, заключивший с ВУЗом договор на оказание образовательных услуг, просрочил оплату. Конечная дата оплаты за указанные университетом услуги также должна быть в обязательном порядке указана в гражданско-правовом договоре.

Все основания для расторжения гражданско-правового договора представителями высших учебных заведений Российской Федерации в одностороннем порядке должны быть прописаны в самом договоре об оказании возмездных образовательных услуг. В ином случае обучающийся человек может обратиться в суд.

В последнее время в России Министерством науки и высшего образования и Правительством Российской Федерации были приняты нормативно-правовые акты, в которых просматриваются элементы гражданско-правового регулирования отношений в области платного высшего образования. Окончательно были утверждены: стандартная форма правового договора об оказании возмездных услуг в сфере высшего образования и сами правила оказания образовательных услуг.

Сама специфика предмета гражданско-правового договора об оказании возмездных услуг в области образования имеет неоднородный состав. Предмет гражданского договора об образовании состоит из следующих важнейших элементов:

- сама образовательная деятельность;

- не овеществленный результат этой деятельности, который выражается в приобретенных навыков, знаний, умений.

Поэтому гражданские отношения, которые вытекают из деятельности высшего учебного заведения по оказанию определенных образовательных услуг, являются имущественными. Отношения же по поводу приобретенных умений, навыков, знаний по своей гражданскоправовой природе относятся к личным и неимущественным отношениям, но которые так или иначе неразрывно связаны с имущественными.

Влияние международной образовательной правовой системы на российское образование достаточно сильное. Это и переход российской системы на болонскую систему образования и внедрение профессиональных стандартов. Нельзя не отметить, тот факт, что международное образование в целом положительно повлияло на российскую систему образования.
Договорные отношение в области высшего образования - это отдельный вид правовых и гражданских отношений. Ярким примером договорных отношений в сфере образовательных услуг высших учебных заведений является предоставление российским гражданам различных возмездных образовательных услуг. Рассмотрим особенности на конкретном примере.

С позиции гражданского права договор об оказании возмездных услуг в области высшего образования имеет своим предметом только услугу и вводит ее в состав определенной группы объектов гражданских прав. Услуга - это определенный акт, результат которого неотделим от самой деятельности по ее оказанию.

На такие образовательные услуги распространяются действия нормы главы 39 Гражданского кодекса Российской Федерации «Возмездное оказание услуг».

Наиболее востребованной на сегодня образовательной услугой в Российской Федерации является получение высшего образования, в т.ч. на платной основе. Причем такую возможность предоставляют как государственные, так и негосударственные ВУЗы. Это открывает более широкие возможности для потенциальных абитуриентов.

Сама возможность получения высшего образования на платной основе создает для выпускников общеобразовательных школ, колледжей и техникумов поступать в высшие учебные заведения вне приема за счет средств государства, чего никогда не наличествовало в Советском Союзе. В те времена получить высшее образование было гораздо сложнее.

Благодаря тому, что платные услуги предоставляют не только государственные высшие учебные заведения, но и негосударственные ВУЗы, рынок возмездных образовательных услуг в сфере высшего образования получил колоссальный толчок. Помимо этого, среди самих граждан Российской Федерации потребность в получении высшего образования также значительно возросла. Поэтому выросла необходимость постоянно повышать эффективность в регламентировании договорных отношений в высших учебных заведениях.

Применение правовых договоров в сфере высшего образования началось именно тогда, когда чиновники из Российской Федерации подписали знаменитую Болонскую декларацию. Это событие означало вхождение России в Болонский процесс. Конечная цель подписания этого международного правового договора - создание единого пространства в области образования на территории всей Европы. 
Необходимо отметить, что именно вхождение Российской Федерации в единое образовательное пространство на территории Европы являлось одним из обязательных пунктов для вхождения нашей страны во Всемирную торговую организацию. Также без этой позиции невозможно было дальнейшее развитие и модернизация российской системы высшего образования.

Для того, чтобы общеобразовательная система в России и система высшего образования полностью соответствовала международным требованиям, Правительству и Министерству науки и высшего образования Российской Федерации необходимо провести следующие действия: создать новейшие современные правовые нормативные акты, которые будут способны обеспечить стабильность работы высших учебных заведений РФ; сформировать в Российской Федерации современное информационное общество.

Очевидно, если сравнивать с 1991 г., работы в данном направлении было проделано немало. Тем не менее, на данный момент времени в правовом законодательстве Российской Федерации, регулирующих правовые вопросы в образовательной системе, все еще имеются «узкие» проблемные места.

Большую роль в формировании в России современного информационного общества должна играть образовательная программа, начиная с первого класса общеобразовательной школы. Ее необходимо в срочном порядке пересмотреть, так как она уже на сегодняшний день не соответствует актуальным реалиям современного общества.

Также немалая роль в формировании в Российской Федерации современного информационного общества лежит на плечах родителей. Хотя многие с этим фактом не согласятся, но это обстоятельство верно, прежде всего, потому, что проще всего вверить свое любимое чадо учителям, чем самому ежедневно и кропотливо заниматься с ним и повышать уровень образовательной подготовки.

В нашем государстве необходимо полностью унифицировать статус высших учебных заведений, а также создать нужные условия для работы единого образовательного европейского пространства.

Федеральный закон «Об образовании» частично решает данную проблему, но на сегодняшний момент времени все еще необходимы дополнительные законодательные инициативы в сфере высшего образования.

Также этот закон установил определенные принципы государственной политики и правового регулирования в области правовых отношений в ВУЗах Российской Федерации. Один из этих принципов гласит: «...сочетание государственного и договорного регулирования правовых отношений в сфере образования». То есть Россия без регулирования правовых отношений в сфере высшего образования не мыслит себя как страна, приоритетом которой являются права граждан.

На сегодняшнее время в области высшего образования существуют следующие виды договорного правового регулирования:

- индивидуальное и нормативное правовое регулирование;

- децентрализованное правовое регулирование;

- централизованное правовое регулирование;

- частноправовое договорное правовое регулирование;

— публично-правовое регулирование.

При децентрализованном нормативном правовом регулировании оба субъекта правоотношений имеют одинаковые права. Это обстоятельство верно и в том случае, если эти два субъекта правовых отношений выступают по отношению друг к другу в публично-правовых отношениях.

При централизованном же регулировании на одной чаше весов находится некий субъект, который обладает властью по отношению к другому гражданскому лицу или группе лиц. Властный субъект устанавливает содержание правоотношения, а другие субъекты ему подчиняются.

Частноправовое договорное правовое регулирование характеризуется преобладанием корпоративных и персональных потребностей, а также индивидуальных начал. В частном праве, благодаря свободе волевого поведения одного из субъектов, который находится в определенном отношении децентрализованной координации, а также равноправных отношений с другими субъектами правовых связей.

Частноправовое договорное правовое регулирование наиболее часто осуществляется при помощи индивидуально-договорных правовых актов. Примеры таких актов: гражданско-правовой договор по оказанию образовательных услуг в каком-либо ВУЗе, трудовой договор.

Для публично-правового регулирования характерен следующий момент: проникновение договорных начал в область публичного права происходит весьма неравномерно. То есть, в некоторых областях публичного права (административное, финансовое, конституционное, муниципальное) договорное регулирование является распространенным явлением. А, например, в некоторых 
других областях (налоговое право, уголовное право) регулирование отношений весьма затруднено.

Образовательные же услуги являются одним из самых перспективных направлений для публичного права. Особенно это касается различных исследований в данной области. Так как образовательные высшие учебные заведения имеют изначально статус публичных. И сами услуги, которые предоставляют эти учреждения также являются публичными. Самый яркий пример такой услуги: платные образовательные услуги в области высшего образования.

Субъекты публичного права обычно имеют наличие компетенции, то есть имеется в наличии разграничение предметов ведения и властных полномочий, которые обычно пересекаются между различными уровнями государственной власти. Поэтому необходимость в данном конкретном случае правового договорного регулирования объективна во всех смыслах.

На сегодняшний момент в Российской Федерации в области правотворчества высшего образования имеются в наличии следующие уровни компетенции: уровень образовательного учреждения, муниципальный, федерально-региональный, региональный и федеральный.
Каждый из этих уровней имеет договорное и правовое регулирование в сфере образования.

Для публично-правового регулирования наблюдается преобладание нормативных договорных актов над индивидуальными договорами. Связано данное обстоятельство прежде всего спецификой публичного правотворчества.

В общем, для публично-правового регулирования характерен императивный способ правового регулирования. Но с каждым годом в России происходит расширение области применения правового договорного регулирования в различных сферах публичного права. Данное расширение предполагает сочетание диспозитивности и императивности правового регулирования. В частности, данное обстоятельство характерно для правотворчества в ВУЗах России.

Таким образом, гражданско-правовые договорные отношения в сфере высшего образования в современных условиях в РФ еще находятся на стадии развития. Для того, чтобы полностью соответствовать международным правовым нормам нужно будет частично переработать некоторые законодательные акты и создать в стране определенные условия.

\section{ЛИТЕРАТУРА}

1. Балабанова А.В. Интеграционные процессы как тренд глобального общественного развития // Ученые записки Российской Академии предпринимательства. 2019. Т. 18. № 4. С. 9-20.

2. Гнездова Ю.В., Хриптулов И.В., Лаврушин В.М., Алексеев А.Н., Земляк С.В., Киященко Л.Т., Шеломенцева М.В., Злотникова Г.К., Сергиенко Н.С., Балынин И.В., Матвеева Е.Е., Мыльникова Л.А., Рейхерт Н.В., Сапожникова С.М., Семченкова С.В., Кокодей Т.А., Кузьменкова В.Д., Ломаченко Т.И., Пахомова А.А., Шишкин Д.В. и др. Самозанятость и креативность в социально-экономическом развитии России. Коллективная монография / Москва, 2019.

3. Захарова 0.Н., Звягинцева А.А., Власов А.В. Мультикультурность и социокультурные проблемы современного общества // Вестник Юридического института МИИТ. 2019. № 2 (26). С. $12-26$.

4. Исматуллоева Н.А. К дискуссии о правовой природе отношений в сфере оказания платных образовательных услуг // Вестник университета (РоссийскоТаджикский (Славянский) университет). 2018. № 2 (62). С. 62-71.

5. Самуйлов В.М., Ревина Е.В. Договорные отношения "вуз-предприятие" // Железнодорожный транспорт. 1997. № 2. С. $65-69$.

6. Кванина В.В. Замена лиц профессорско-преподавательского состава (по договору на оказание возмездных образовательных услуг) // Цивилист. 2006. № 1. C. 54-56.

7. Штепа Т.В. Понятийные признаки образовательной услуги как объекта гражданских прав // Современная наука: актуальные проблемы теории и практики. Серия: Экономика и право. 2020. № 10. С. 219-222.

8. Гибадуллин А.А., Карагодин А.В. Вызовы цифровой экономики в сфере подготовки кадров // Актуальные проблемы экономики и менеджмента. 2019. № 2 (22). С. 33-42.

9. Иванов С.Ю., Иванов А.С., Морковкин Д.Е. Гуменная Н.С. Профессиональные траектории выпускников вузов и их трудовая адаптация // Социодинамика. 2016. № 12. - С. $54-67$.

10. Рудакова Е.Н. Государственная образовательная политика: этапы становления и современное состояние // Вестник Московского государственного областного университета. Серия: История и политические науки. 2012. № 4. С. 175-183.

11. Креативный менеджмент: учебник / под ред. А.А. Степанова и М.В. Савиной. М.: Дашков и К, 2017. 254 с.

12. Батова М.М. Формирование цифровых компетенций в системе "образование - наука - производство" // Вопросы инновационной экономики. - 2019. Том 9. - № 4. - С. 1573-1584. - doi: 10.18334/vinec.9.4.41467.

13. Миндлин Ю.Б. Феномен бюрократии // Современная наука: актуальные проблемы теории и практики. Серия: Гуманитарные науки. 2012. № 1. С. 3-6.

14. Штепа Т.В. Правовой статус субъектов договора возмездного оказания образовательных услуг // Проблемы экономики и юридической практики. 2020. 
T. 16. № 5. C. $227-230$.

15. Serykh A.B., Grudtsina L.Yu., Votinov A.A., Abramova N.G., Gaidamashko I.V., Morkovkin D.E. Algorithm of teacher projecting and training activity in the process of student social-right culture formation // Astra Salvensis. 2018. T. 6. № 2. P. 329-346.

16. Ivanova I.A., Odinaev A.M., Pulyaeva V.N., Gibadullin A.A., Vlasov A.V. The transformation of human capital during the transition to a digital environment // B сборнике: JOP Conference Series: Metrological Support of Innovative Technologies. Krasnoyarsk Science and Technology City Hall of the Russian Union of Scientific and Engineering Associations. Krasnoyarsk, Russia, 2020. C. 32024.

17. Pulyaeva V.N., Gibadullin A.A., Usmanova T.J., Ivanova I.A., Rudakova E.N., Dmitrieva 0.A. Formation of modern requirements for the development of humen capital in the context of increasing the efficiency of the industrial potential // B сборнике: JOP Conference Series: Metrological Support of Innovative Technologies. Krasnoyarsk Science and Technology City Hall of the Russian Union of Scientific and Engineering Associations. Krasnoyarsk, Russia, 2020. C. 32020.

( Власов Александр Викторович (alessandro.vlasov@mail.ru), Штепа Татьяна Владимировна (t.v.shtepa@mail.ru),
Морковкин Дмитрий Евгеньевич (MorkovkinDE@mail.ru).

Журнал «Современная наука: актуальные проблемы теории и практики»

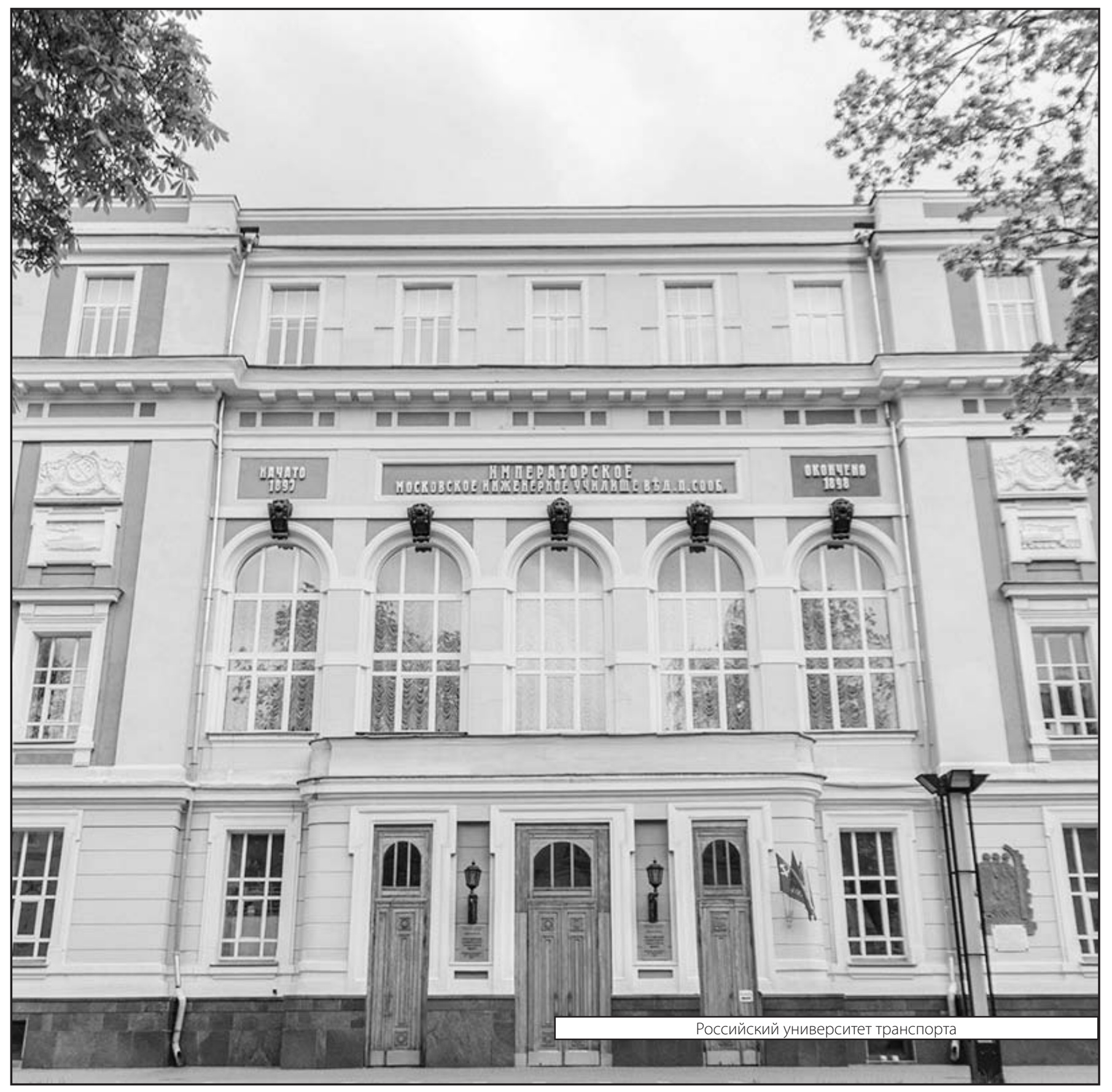

